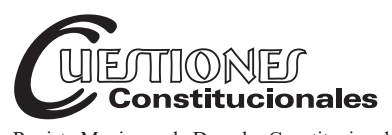

Revista Mexicana de Derecho Constitucional Núm. 39, julio-diciembre 2018

\title{
Las revistas jurídicas y su papel en la Constitución ${ }^{1}$
}

La Red de Revistas en Derecho Constitucional realizó, el 3 de febrero de 2017, en el Palacio de Minería, una mesa de debate que buscó respuestas para tres preguntas: a) ¿son o deben ser las revistas científicas parte del pensamiento crítico de la Constitución?; b) ¿apoyan las revistas científicas a la (in)estabilidad de la Constitución?, y c) ¿qué hacer para publicar en una revista indexada?

Sobre la pregunta a) (pensamiento crítico), es necesario inicialmente hacer algunas reflexiones sobre las funciones de la doctrina y la jurisprudencia (decisiones judiciales) en El Estado constitucional. ${ }^{2}$ Es innegable que la jurisprudencia actualmente tiene una posición de destaque, pero las revistas científicas son fundamentales para el pensamiento crítico de la Constitución. Dos ejemplos sobre la jurisprudencia.

Primero: hay investigaciones y procesos penales acerca de actos de corrupción que envuelven a la gran mayoría de élite política brasileña e importantes empresas y empresarios. Esos procesos producen relevantes decisiones acerca de las garantías procesuales y de los derechos fundamentales procesuales. En verdad, fue introducida en Brasil la colaboración 8.072/90 (Ley de los Crímenes Hediondos); todavía el gran impacto fue causado por la Ley 12.850/2013.

Segundo: el uso de lo sistema de precedentes (stare decisis) fue una importante adopción del Nuevo Código de Proceso Civil brasileño de 2015.

1 Trabajo presentado en la Red de Revistas de Derecho Constitucional el 3 de febrero de 2017, dentro del XIII Congreso Iberoamericano de Derecho Constitucional.

2 Cfr. Marrafon, Marco Aurélio y Robl Filho, Ilton Norberto, "Las fuentes jurídicas y el Estado democrático y social: la crisis y notas para su superación”, Cuestiones Constitucionales. Revista Mexicana de Derecho Constitucional, núm. 33, julio-diciembre de 2015, pp. 105-132. 
Estableció el artículo 926 del Código: "los tribunales deben uniformizar su jurisprudencia y mantenerla estable, íntegra y coherente".

La ampliación del papel de la jurisprudencia ha producido dos fenómenos. En primer lugar, se observa una ampliación del realismo jurídico jurisprudencial. Por ejemplo, un juez (ministro) del Superior Tribunal de la Justicia — STJ (responsable por la uniformización de la interpretación de las leyes federales) — ha dicho: "No me importa lo que piensan los doctrinadores" (STJ, voto de Humberto Gomes de Barros, AgRg nos Embargos de Divergência em Resp 279.889). Un juez de la Suprema Corte brasileña constantemente dice que: "el derecho es lo que los tribunales dicen que es".

Por otra parte, se observa una importante función de la doctrina en la conformación (información) de las decisiones judiciales y, especialmente, la reflexión crítica de la doctrina acerca de temas analizados por la jurisprudencia. En este sentido, las revistas científicas de derecho constitucional tienen un papel de destaque, buscando siempre la realización de la crítica cuando hay desconsideraciones de los derechos fundamentales y humanos por cualquiera de los poderes del Estado.

La respuesta a la interrogante $b$ ) (contribución sobre instabilidad o estabilidad constitucional) es: las revistas y la doctrina ayudan en la consolidación del constitucionalismo democrático, haciendo críticas a las estructuras sociales, jurídicas y políticas con inconstitucionalidad. El análisis de los juristas debe producir cambios en la vida cotidiana y en las instituciones, mas esa alteración tiene como objetivo y finalidad las concepciones contemporáneas de la Constitución. Al mismo tiempo, los estudiosos critican postulados y estructuras constitucionales y observan el desarrollo de las libertades de expresión y científica; así como la construcción del libre mercado de ideas, que es esencial para la robusta esfera pública. ${ }^{3}$

Sobre la pregunta $c$ ), la publicación en periódico indexado presupone una profunda comprensión de la literatura especializada y por consecuencia de las revistas jurídicas, así como los debates jurisprudenciales más importantes. También es esencial la presentación y la elaboración de nuevas reflexiones, propuestas y concepciones jurídicas que ayuden en

3 Cfr. Robl Filho, Ilton Norberto y Sarlet, Ingo Wolfgang, "Freedom of Speech in the Federal Constitution of Brazil and the Problem of its Collision with other Fundamental Rights, Particularly Personality Rights", Przegld Prawa Konstytucyjnego, vol. 34, 2016, pp. 133-163. 
la mejor comprensión del derecho y la sociedad. ${ }^{4}$ En verdad, las revistas especializadas buscan contribuciones originales.

Fue un gran honor mi participación y de la revista Constituição, Economia e Desenvolvimento: Revista da Academia Brasileira de Direito Constitucional en la mesa con los profesores Paola Andrea Acosta Alvarado, Edgar Corzo Sosa, Juan Fernando Durán Alba y Andrea Morrone.

Ilton Norberto RoBl FILHO*

4 Robl Filho, Ilton Norberto y Frota, Pablo Malheiros da, "Pesquisa jurídica: entre a qualidade e a quantidade", en Silveira, Vladmir Oliveira da et al. (org.), Educação Jurídica, São Paulo, Saraiva, pp. 229-252.

* Doctor en derecho por la Universidade Federal do Paraná. Profesor en el Instituto Brasiliense de Direito Público e en la Universidade Federal do Paraná. Editor de Constituição, Economia e Desenvolvimento: Revista da Academia Brasileira de Direito Constitucional.ilton@abdconst.com.br. 